\title{
INFORMES*
}

\section{La Agencia Tributaria de Andalucía}

\section{INTRODUCGIÓN: LA AGENCIA TRIBUTARIA DE ANDALUCÍA Y LA ADMINISTRACIÓN TRIBUTARIA DE LA JUNTA DE ANDALUCÍA}

Una vez más el último año de la legislatura se despide con avalancha legislativa. La originalidad de esta ocasión es que la corriente ha alcanzado a nuestra Comunidad Autónoma que, por primera vez en su historia, traspasa la barrera de las veinte leyes anuales llegando a la cota de veinticuatro. Todo un hito legislativo, por el que es de justicia felicitar a los legisladores. Si además las leyes son de calidad y efectivamente se cumplen podemos prometernos un halagüeño futuro en Andalucía.

Uno de los aspectos en que, sin duda, se han alcanzado importantes niveles de renovación ha sido el organizativo, acaso aprovechando el impulso derivado de la aprobación de la reforma del Estatuto de Autonomía por Ley Orgánica 2/2007, de 19 de marzo. Así ocurre con la Ley 23/2007, de 18 de diciembre por la que se crea la Agencia Tributaria de Andalucía y se aprueban medidas fiscales.

La Ley tiene su causa en el artículo 181 del nuevo texto estatutario que, al parecer, considera que la organización de la Administración tributaria de la Comunidad Autónoma que mejor responde a los principios previstos con carácter general en la Constitución y en el presente Estatuto, velando especialmente por la efectiva aplicación de los recursos a su cargo y luchando contra el fraude fiscal es la Agencia Tributaria que se crea por ley a la que se encomendará la gestión, liquidación, recaudación e inspección de todos los tributos propios, asi como, por delegación del Estado, de los tributos estatales totalmente cedidos a la Junta de Andalucía.

Se crea, por tanto, la Agencia Tributaria de Andalucía (en adelante la Agencia) en el marco de la Administración Tributaria de la Junta de Andalucía (Sección segunda del capítulo primero) integrada por el conjunto

\footnotetext{
1 Esta Sección ha sido preparada bajo la dirección de José Ignacio MORILLO-VELARDE
} PÉREZ. 
de órganos de la Consejería competente en materia de Hacienda y de la Agencia a los que correspondan las funciones de aplicación de los tributos, potestad sancionadora y revisión en vía administrativa, de acuerdo con lo dispuesto en el Estatuto de Autonomía para Andalucía, en la presente Ley y en la demás normativa de aplicación (art. 5.1).Dentro de este esquema la Consejería de Hacienda -sea cual sea su denominación- fija la política tributaria de acuerdo con las directrices que marque el Consejo de Gobierno y queda en manos de la Agencia la aplicación de los tributos, incluidos el impulso, coordinación y control de actividades. Se mantiene el criterio tradicional de la separación de las funciones de aplicación de los tributos y la resolución de las reclamaciones económico-administrativas.

Para completar el diseño de la Administración tributaria, se crea la Oficina para la Defensa del Contribuyente adscrita a la Consejería competente en materia de Hacienda, para velar por la efectividad de los derechos de los ciudadanos en sus relaciones con la Administración tributaria de la Junta de Andalucía. Su estructura y régimen de funcionamiento se regulará mediante Decreto del Consejo de Gobierno.

No creo que deban entenderse de modo literal las expresiones a través de las que se procura delimitar la llamada Administración tributaria, respecto el conjunto de la Administración autonómica andaluza que se aparta de la solución impuesta habitualmente en nuestro Derecho, el llamado criterio subjetivo o de la personalidad jurídica. La Ley andaluza, siguiendo a cierta distancia a la propia Ley estatal (Ley 58/2003, de 17 de diciembre, General Tributaria) adopta un curioso criterio mixto orgánico no personalista para delimitar dicha Administración -órganos de la Consejería competente en materia de Hacienda y de la Agencia-, por tanto, estaríamos hablando de órganos de dos Administraciones públicas diferentes unificados bajo el criterio objetivo o funcional: a los que correspondan las funciones de aplicación de los tributos, potestad sancionadora y revisión en vía administrativa. La consecuencia de la citada literalidad es que hay órganos de la consejería de Hacienda y órganos y de la Agencia que no se integran en la Administración Tributaria y consecuentemente la situación inversa. El primer supuesto no reviste especial importancia ya que la consejería puede atender otro tipo de cuestiones, sin embargo no parece razonable pensar que la agencia tributaria, calificada como una agencia especial, no agote en su estructura el ser Administración tributaria y pueda asumir otros cometidos administrativos, que formarían parte de la Agencia sin ser Administración tributaria. En mi opinión estamos ante una mera descripción de la Administración tributaria, que pese a proceder del legislador no tiene fuerza suficiente para crear ninguna Administración ex novo, sino simplemente subrayar un aspecto de la Administración pública andaluza. 


\section{NATURALEZA DE LA AGENCIA}

La Agencia Tributaria de Andalucía se crea como agencia de régimen especial para realizar, en régimen de autonomía de gestión, las actividades administrativas de aplicación de los tributos y las demás funciones y competencias referidas en el artículo 6 de la presente Ley (art. 1.1 ); como no podía ser menos, tiene personalidad jurídica pública diferenciada y patrimonio y tesorería propios, sin perjuicio del principio de unidad de caja (art. 1. 2).

La calificación de agencia de régimen especial remite a una de las categorías de agencia que crea la Ley 9/2007, de 22 de octubre, de Administración de la Junta de Andalucía (LAJA). Como agencia de régimen especial se atribuye cualesquiera de las actividades mencionadas en los artículos 65.1 y 68.1 LAJA siempre que se les asignen funciones que impliquen ejercicio de autoridad y requieran especialidades en su régimen jurídico.

En virtud del primero de los preceptos citados -que contempla las funciones de las agencias administrativas- se atribuye a las de régimen especial la realización de actividades de promoción, prestacionales, de gestión de servicios públicos y otras actividades administrativas en ejecución de programas específicos de la actividad de una consejería, por el mandato del segundo -referida a las agencias públicas empresariales- se atribuye la realización de actividades prestacionales, la gestión de servicios o la producción de bienes de interés público susceptibles de contraprestación. Se introduce así una idea de mixtificación donde es difícil separar lo que corresponde a uno u otro origen, si no fuera por la referencia del primero de los preceptos citados a las competencias de una consejería. Un dato ciertamente formal y de naturaleza en muchos casos arbitraria. Al final todo se resuelve con la apelación al ejercicio de autoridad y la necesidad de un régimen especial.

Como Agencia de régimen especial, la tributaria se rige por el Derecho Privado, excepto en las cuestiones relacionadas con la formación de la voluntad de sus órganos y con el ejercicio de las potestades administrativas que tengan atribuidas y en los aspectos específicamente regulados en la ley de creación, en sus estatutos, en la Ley General de la Hacienda Pública de la Comunidad Autónoma de Andalucía y demás disposiciones de general aplicación (art. 712 LAJA).

Concretando estas previsiones el art. 3 determina que la Agencia se regirá por su ley de creación, por su estatuto y por las demás normas que los desarrollen, en el marco de la normativa de la Comunidad Autónoma aplicable a las agencias de régimen especial en lo que no se oponga dicha ley. En materia 
económico-financiera, de control y contabilidad será de aplicación a la Agencia el régimen establecido en la Ley 5/1983, de 19 de julio, de hacienda de la comunidad autónoma para las entidades contempladas en el artículo 6.1.b) de la misma, esto es las en virtud de la ley hayan de ajustar su actuación a Derecho privado, salvo el régimen presupuestario, que se regirá por lo dispuesto en el artículo 25 de la ley de creación que viene a consagrar una especie de autonomía financiera en el contexto del presupuesto de la Comunidad Autónoma, sujeto sin embargo a los controles económico financieros correspondientes (art.26).

En el desarrollo de sus actividades de aplicación de los tributos, la Agencia actuará de conformidad con el sistema de fuentes del ordenamiento tributario al que se refieren los artículos 5.3 y 7 de la Ley 58/2003, de 17 de diciembre, General Tributaria, en los términos previstos en el artículo 180.1 y 2 del Estatuto de Autonomía para Andalucía y, en particular, con las normas aprobadas por la Comunidad Autónoma en las materias de su competencia y con las que regulen la cesión de tributos del Estado. Cuando gestione tributos locales, se ajustará a la legislación reguladora de las Haciendas Locales (art. 3.3).

A la vista de estos preceptos se concluye que la aplicación del Derecho privado en la vida de la Agencia no tiene sino un margen muy estrecho, acaso por ello la ley de creación no menciona este extremo que es, sin embargo, una de las notas características de las agencias de régimen especial. En ese sentido y a diferencia de lo que sucede con las agencias de régimen especial, cuyo personal se rige por el Derecho laboral a excepción de las funciones que impliquen ejercicio de autoridad serán desempeñadas por personal funcionario, que se regirá por la normativa aplicable en materia de función pública (art.74 LAJA), el de la Agencia no se adscribe preferentemente a ninguna de las dos posibilidades, sino que la Agencia dispondrá del personal funcionario y laboral necesario para su funcionamiento. Aplicándose la regla general de que los puestos de trabajo que comporten ejercicio de funciones que impliquen la participación directa o indirecta en el ejercicio de las potestades públicas o en la salvaguardia de los intereses generales de la Administración pública se reservarán al personal funcionario. Este personal se regirá por la normativa aplicable en materia de función pública, con las peculiaridades previstas en esta Ley y las que, en su desarrollo, se establezcan en su Estatuto.

En materia de contratación y patrimonio la Agencia se somete al régimen ordinario de las demás Administraciones públicas.

\section{EL CONTRATO DE GESTIÓN Y EL PLAN DE ACGIÓN ANUAL}

Para comprender el carácter especial de esta agencia es necesario aludir al contrato de gestión como pieza básica de su funcionamiento y el plan de 
acción anual, instrumento vinculado y dependiente de aquél. A través de estos mecanismos es como se produce la verdadera conexión de la Agencia con las denominadas en la LAJA agencias de régimen especial. En ellos se definirán los objetivos a perseguir, los resultados a obtener y, en general, la gestión a desarrollar, así como los siguientes extremos en los que la Ley de creación de la Agencia sigue casi literalmente a la LAJA:

a) Los recursos personales, materiales y presupuestarios a aportar para la consecución de los objetivos.

b) Los efectos asociados al grado de cumplimiento de los objetivos establecidos por lo que hace a exigencia de responsabilidad por la gestión de los órganos ejecutivos y el personal directivo, asi como el montante de masa salarial destinada al complemento de productividad o concepto equivalente del personal laboral.

c) Los demás extremos que se establezcan mediante forma conjunta de las Consejerías competentes en materia de Administración Pública y de Hacienda,

El contrato de gestión será aprobado por el Consejo de Gobierno y tendrá una vigencia de tres años, $u$ otra distinta si asi lo especifica el acuerdo de aprobación. Finalizada su vigencia, la persona titular de la Consejería competente en materia de Hacienda informará al Consejo de Gobierno sobre su ejecución y resultado.

Es inútil preguntarse por la naturaleza contractual del contrato de gestión. Más útil es indagar se conexión con la figura del mismo nombre regulada en el art. 13 de la Ley 28/2006, de 18 de julio, de Agencias estatales para la mejora de los servicios públicos. El contrato de gestión y el plan de acción constituyen las claves que dan sentido a la propia existencia de estas Agencias: la actuación de las Agencias Estatales se produce, con arreglo al plan de acción anual, bajo la vigencia y con arreglo al pertinente contrato plurianual de gestión (art. 13.1), pues con estas no se pretende sino crear un entorno adecuado y favorable a la actuación por objetivos. Parece, pues, que puede afirmarse que las agencias especiales andaluzas coinciden con la figura de las agencias estatales, al tiempo que las agencias administrativa y las agencias públicas empresariales serían las réplicas de los organismos autónomos y de los entidades públicas empresariales de la Ley 6/1997, de 14 e abril, de Organización y Funcionamiento de la Administración General del Estado. Así una técnica adjetiva e instrumental configura una nueva tipología de entes públicos. Hay que reconocer que en este punto la legislación andaluza gana a la estatal en rigor conceptual y sistemático. 
El plan de acción anual, que será aprobado por el Consejo Rector de la Agencia, fijará los objetivos que se alcanzarán en el ejercicio, ajustándose a las directrices y orientaciones de la Consejería competente en materia de Hacienda y a las previsiones plurianuales del contrato de gestión.

Tanto el contrato de gestión como el plan de acción anual son instrumentos normativos que trazan los objetivos y regulan la actividad de estas agencias durante periodos de tiempo diferentes y a nivel funcional también diferente, por más que formalmense se escenifique un entorno contractual. A este respecto es muy significativa la estructura organizativa de nuestra Agencia. Como enseguida veremos la Agencia Tributaria Andaluza es una organización paralela a la Consejería de Hacienda de la Junta de Andalucía, dotada de personalidad jurídica que, de esta forma, justifica el contrato con la Administración autonómica y su pretendida mayor agilidad de funcionamiento.

\section{ORGANIZACIÓN DE LA AGENCIA}

De acuerdo con lo que establece el art. 10 de su ley de creación la Agencia se estructurará en los órganos de gobierno, ejecutivo y de control previstos en la propia ley, y en los complementarios que se determinen en su Estatuto. A estos efectos se considera órganos de gobierno: a) La Presidencia. b) La Vicepresidencia y c) El Consejo Rector. La Dirección de la Agencia tiene el carácter de órgano ejecutivo. Además en el seno de la Agencia existirá una Comisión de Control,

Sin embargo, lo más interesante de esta estructura organizativa es su relación y ajuste con la Consejería de hacienda. Así, la presidencia de la Agencia corresponderá al viceconsejero de hacienda, la vicepresidencia a las secretaría competente en materia de hacienda, pero donde se ve aún más clara la interdependencia entre la Agencia y la consejería es en la composición del consejo rector que se integra por el presidente de la Agencia, el vicepresidente, el director general en materia de tributos, el director de la agencia y seis vocales nombrados por el Consejo de Gobierno a propuesta del consejero de hacienda, para completar con la atribución al consejero de hacienda de asistir a las sesiones del consejo rector en cuyo caso lo presidirá como miembro de pleno derecho con voz y voto. Visto de otra manera, se puede afirmar que el consejero de hacienda es el presidente natural de la Agencia Tributaria de Andalucía. Quizá simplificando, lo que a veces puede ser bueno podemos decir que la Agencia Tributaria de Andalucía es la consejería de hacienda revestida de una personalidad jurídica particular. 


\section{FUNCIONES Y PRINCIPIOS GENERALES DE ACTUACIÓN DE LA AGENCIA}

Las funciones de la Agencia son las típicas de un Administración tributaria de conformidad con el carácter de núcleo de la Administración tributaria de Andalucía que le corresponde, el rasgo peculiar deriva precisamente de la estructura tributaria propia de Comunidad Autónoma con tributos propios, cedidos y con la posibilidad de gestionar tributos locales. Así podemos señalar las siguientes funciones:

a) La gestión, liquidación, recaudación e inspección de todos los tributos propios, de acuerdo con lo dispuesto en el artículo 181.2 del Estatuto de Autonomía para Andalucía.

b) La gestión, liquidación, recaudación e inspección, por delegación del Estado, de los tributos estatales totalmente cedidos a la Comunidad Autónoma, de acuerdo con lo dispuesto en el artículo 181.2 del Estatuto de Autonomía para Andalucía.

c) La gestión, liquidación, recaudación e inspección de los recargos que puedan establecerse sobre los tributos estatales.

d) El ejercicio de la potestad sancionadora en relación con todos los tributos y recargos cuya aplicación corresponda a la Agencia.

e) La recaudación en periodo ejecutivo de los ingresos de Derecho público de naturaleza no tributaria de la Comunidad Autónoma.

f) La revisión en vía administrativa de los actos y actuaciones de aplicación de los tributos, de ejercicio de la potestad sancionadora en materia tributaria y de recaudación en periodo ejecutivo de los demás ingresos de Derecho público de la Comunidad Autónoma, salvo las reclamaciones económicoadministrativas y la revisión de actos nulos de pleno derecho.

g) Las que se le atribuyan por el Consejo de Gobierno en relación con los demás tributos del Estado recaudados en Andalucía en aplicación de lo dispuesto en el artículo 180.3 del Estatuto de Autonomía para Andalucía.

h) La colaboración y coordinación con las demás Administraciones tributarias y, en particular, la participación en el Consorcio al que se refiere el artículo 181.2 del Estatuto de Autonomía para Andalucía, sin perjuicio de las atribuciones de la Consejería competente en materia de Hacienda.

i) Las que pueda asumir por delegación en relación con la aplicación de los tributos locales, de acuerdo con lo previsto en el artículo 181.4 del Estatuto de Autonomía para Andalucía.

j) Las que le atribuyan expresamente las leyes de Andalucía y los reglamentos dictados de conformidad con las previsiones específicas de una ley, así como cualquier otra actividad, competencia o función que específicamente se 
le atribuya en relación con los tributos y demás ingresos de Derecho público de la Comunidad Autónoma de Andalucía.

Conviene subrayar que, como es tradicional en la Administración tributaria española se mantiene la separación entre la gestión de los tributos y la revisión en vía económico-administrativa, sin perjuicio de los procedimientos especiales de revisión y el recurso de reposición conforme a lo establecido en el art. 213 de 1 Ley 58/2003, de 17 de diciembre, General Tributaria.

\section{A MODO DE BALANCE FINAL}

Para finalizar un breve juicio sobre la nueva Agencia. Bienvenida un organismo más a la nutrida nómina de organismos: Agencias, Institutos, organismos etc de nuestra cada vez más complicada Administración andaluza. Esta vez sirve de justificación la reforma del Estatuto y la incorporación de una nueva moda burocrática cual es el llamado contrato de gestión, una variante más de los famosos contratos-programas que en los últimos años se están haciendo ominipresentes en todos los niveles y ámbitos de la actuación administrativas, posiblemente en un impulso inicial de mejora que cuando se generaliza se tiñe de rutina y formalismo y termina condiciando al escollo que se intentó evitar: la ineficacia. 